\title{
Evaluation of an Educational Interactive Software for Microscopic Phenomena Related to the Structure of Matter
}

\author{
Anargyros Drolapas, Ourania Gkikopoulou, George Kalkanis \\ National and Kapodistrian University of Athens \\ Greece
}

\begin{abstract}
A study about the evaluation and the presentation of a new educational interactive software that deals with physical phenomena like the structure of matter in a microscopic level using animated representations. This software was designed to be used for teaching basic concepts about the structure of atomic models and matter, aiming to help pupils to spot the differences in structure between solid, liquid and gas state. By visualising expansion and contraction, as well as the correlation between temperature and the speed of particle movement in matter. The presentation of the software is accompanied by the results of its use in the classroom, where it is reflected that it has helped to cope with cognitive difficulties that are widely reported in the bibliography
\end{abstract}

\section{Introduction}

The effectiveness of the educational models that teacherschoose in order to communicate basic concepts of science to their pupils is continuously under question. In particular lessons about physics and chemistry where many concepts are about phenomena that cannot be observednot event through an electronic microscope. For example the representation of the basic structures of matter such as: the atomic model, particle physics, electron interactions and movements etc.Usually the educational material that we, the teachers, use are sketches and artistic representations which can be confusing for pupilsbecause refers to concepts that cannot be approached by senses [2, 5, 7]. The process of choosing the ideal educational model is complicated. Which model is "better"? An older simplifiedone that can be used to a wide age group of pupils or a modern one more complex but more accurate in terms of modern physics? Another parameter that we tend to forget due to technical difficulties is that everything in matter is constantly moving. Atoms, molecules, electrons are in a constant motion, but most of the educational materials are lacking that movement.In other words we try to teach the properties of matter with images that stay unchangeable expecting that the pupils will comprehend the model, will imagine successfully how the model moves and how interacts.All these high expectations occurwithout having tools to test the possible and impossible assumptions that a learner's mind might produce. This current work,that we present here, is a proposal of how we can deal with both modeling problems and the construction of interactive/moving representations of basic phenomena through a microscopic point of view. In a way we are trying to provide a solution to a lapse of educational material for many physical phenomena.

\section{The phenomena}

The initial idea of our project was to work on some basic physical phenomena that are widely presented in Greek educational syllabus in various levels. Starting with primary schools and continuing with Junior High School and High School's syllabus [1]. As cases study,we present the following phenomena:

- the three phases of matter (solid, liquid, gas) and the mechanism of the changes between the states,

- the surface of a liquid (vaporing and boiling),

- thermal expansion,

- movement of electrons in metals (electric current and how metals act as conductors of electricity),

- howsound travels through matter.

Before focusing on the above phenomena, we should mention which atomic modelwe chose as the appropriate for all these subjects.Our process of selecting the atomic model that we use have been documented in our previous work $[3,4,6]$. What we did was to present 5 possible atomic models to pupils and asked them to try to imagine the way that model will interact in various phenomena.

We asked them to evaluate those models before and after their attempt to use them to describe a 
phenomenon. When the pupils tried to draw snapshots of atoms in a molecule bond or the free electrons in a metal, then the evaluation of each model was easier. Some models were able to depict what were the basic principles of each phenomenon, but some didn't. So the pupils were able to choose the atomic model that clearly could work for all the phenomena we have aimed to represent. Many of the pupils have changed their initial evaluation of the models after they have tried to use the model as an educational model.

The result of our research was an atomic model (Figure.1) were the electrons appear to be blurred point objects thatmove in random areas based on probability's density. The viewer experiences it like watching the atom from a distance. The nucleus doesn't have an inner structure, it's just a dot, but there is a constant movement in all the sub atomic particles.

Having done that initial process, then we started creating those representations and we moved to the second stage of our research to present those parts of science syllabus with our educational software and evaluate the comprehensive differences with pupils that were educated with a more classic approach. In the current article, we present the results of our work that was presented in Primary school pupils.

\section{Thesoftware}

A few technical information about the software. Initially it was built with Adobe Flash and Actionscripts, but due to a vast migration from all the Adobe Flash technologies that was decided by all the companies that develop browsers and operating systems, we had to abort that platform. So we were forced to redesign and recreate our software with Html 5 (Canvas) technologies in order to be totally compatible with all the browsers and all the devices. Pupils and teachers can use our applications with their computers, tablets or smart phones there is no need for installing anything more than a browser that supports html5 technologies (most of them do that already).

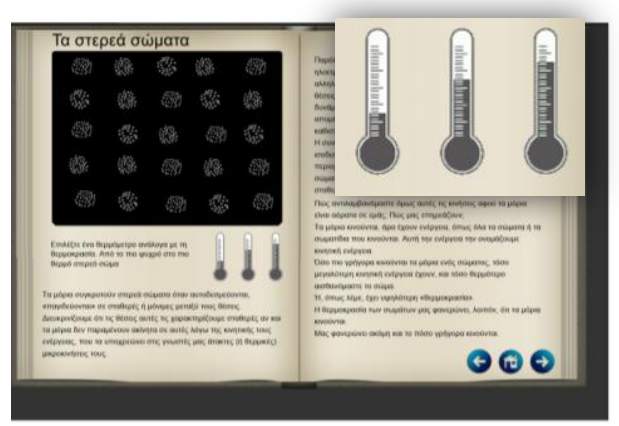

Figure 1. User interface of software
In figure 1 there is a screenshot of the user interface, the basic characteristics of the software are: All the texts are in Greek and are related with the visual material of every page. All the phenomena that we mentioned above are presentedwithinteractivevisualizations. In every of these phenomena there are buttons available for the user to interact.For example, in figure 1 there are three thermometers, when you press these buttons from left to right (that symbolizes a raise of temperature) the user can spot various changes in visualization. For example in a solid state the rise of temperature can increase the speed and the area that each element is moving in having as a result an increase of the distances between atoms that produce the visualization of thermal expansion. Of course, all the atoms in this example and all the molecules in other pages are in a constant movement in a way that represent the chaotic movements of matter. There are also two pages about liquid and gas state of matter where the user can change the temperature and watch the changes in motion and behavior of matter that occur. In a similar way in figure 2 we focus on the visualization window to present how water changes states from liquid to the hexagon structure in ice crystals.

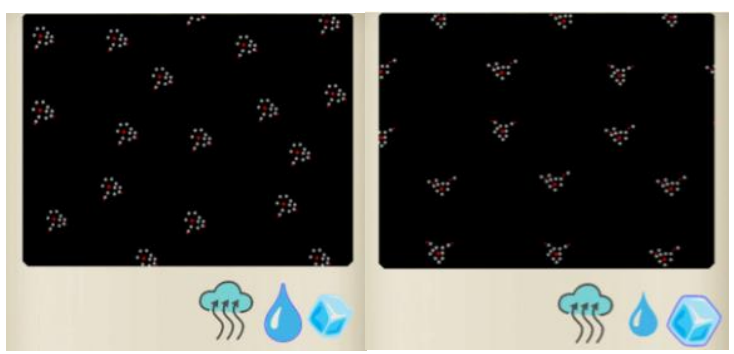

Figure 2. Water as ice and liquid

In a similar manner, the rest of the phenomena we mentioned before are visualized in html pages as can be previewed in figure 3 focusing again in the visualization window and the buttons.
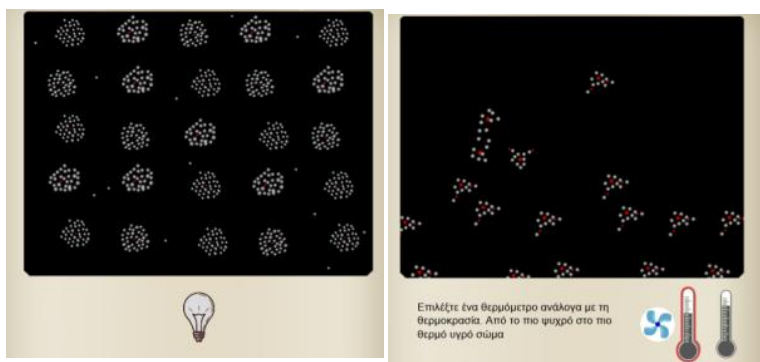

Figure 3. Evaporating water and electrons in
metal

In the visualization on the left in figure 3 we compare the differences between evaporation and 
boiling with or without wind with three buttons about temperature and wind and on the right of figure 3 we present the different type of movement of electrons in metals when there is a potential difference across the conductor and when there is not. There is also optional for the user to watch a collision between an electron and an atom that will produce light emission (Franck-Hertz experiment). Finally, there are similar visualization for sound travelling.

\section{Research:Questions, Method, Hypotheses}

Our research question focuses on exploring whether pupils of primary school are able to comprehend the phenomena in question after the use of the proposed software. For the collection of data we used written documents and sketches of the pupils that participated in our study.

\section{Participants}

The sample was 20 pupils of 6th grade (11-12 years old) of a public elementary school.

\section{Materials -Procedure}

We used 3 questionnaires: A Questionnaire about the states of matter and their changes where pupils were asked to draw sketches of the interior of a solid, a liquid and a gas and explain the evaporation and boiling of water and the expansion of a solid. A Questionnaire about the propagation of sound where pupils were asked to draw sketches and explain how the sound wave propagates in the air. A Questionnaire about electricity where pupils are asked to explain and draw sketches of the movement of electrons in metals when there is a potential difference across the conductor and when there is not.

The same questionnaires were administered to the pupils before (as pre-tests) and after (as post-tests) the implementation of the software, in order to examine the effectiveness of the intervention

Participants recorded their answers and drew their sketches in the questionnaires given to them.

Moreover, at the end of the intervention we administered to the pupils an Attitudes Questionnaire in order to evaluate their satisfaction with the software and the difficulties they encountered.

\section{The intervention}

The intervention with the implementation of the software lasted for 4 hours and included the three states of matter and their changes ( 2 hours), the propagation of sound (1 hour) and electricity (1 hour).

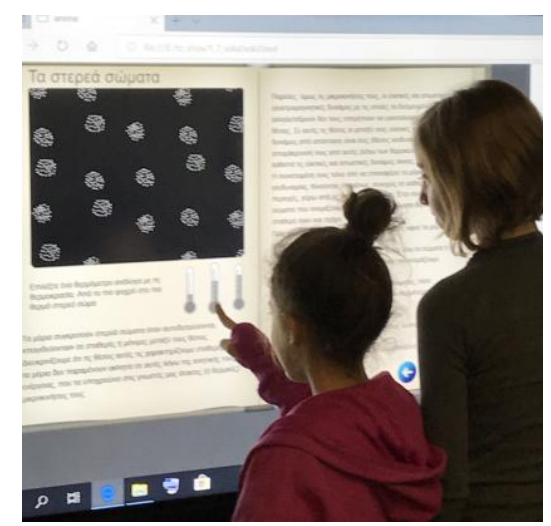

\section{Figure 4. Using the interactive properties of the software}

During these hourspupils were able to use the relevant software and interact with it by changing either the temperature, or the presence of wind on the surface of a liquid, the initiation of a sound wave, etc and observe the results of their interaction. When the temperature waschanging pupils could use a ruler to measure the change of distances between the atoms in matter.

They seemed to enjoy the process and they didn't seem to have any difficulty in using the software.

\section{Results / Discussion}

Based on their answers and their sketches pupils' answers to the questions of the 3 tasks (solid- liquidgas, evaporation, expansion, sound propagation and electricity) were categorized into 4 basic categories of explanations for each phenomenon:

(1) initial explanation, when pupilssimply describe the phenomenon without explaining it or their description is based on the time sequence(score 1).

(2) alternativeexplanation, when pupilsgive some kind of explanation but their explanation contains errors and misunderstandings (e.g. molecules expand, hot molecules-cold molecules, electrons rotate etc.). They mention erroneous procedures or transfer macroscopic properties of matter into the microcosm (score 2).

(3) correct explanation, when pupils give a proper explanation which describes the basic information about the movements or the distances of molecules but not for the whole process: the positions, distances and tracks of the movements of molecules. They draw microscopic sketches without many details concerning the movements of molecules or the distances between them (score 3).

(4) complete explanation, when pupils give a complete scientific explanation which describes the positions, distances and tracks of the movements of molecules (e.g. when the temperature of the solid increases, the speed of the molecules and their 
distances from their permanent positions grows). (score 4).

The categorization of pupils' explanations based on their descriptions as well as their sketches for each phenomenon are shown in table 1 and 2 .

Table 1. Categorization of Pupils' explanations for each phenomenon (pre)

\begin{tabular}{|l|c|c|c|c|}
\hline & \multicolumn{4}{|c|}{ Explanations - pre } \\
\hline & Initial & $\begin{array}{c}\text { Alterna } \\
\text { tive }\end{array}$ & Correct & Complete \\
\hline solid & $15 \%$ & $60 \%$ & $25 \%$ & - \\
\hline liquid & $15 \%$ & $65 \%$ & $20 \%$ & - \\
\hline gas & $15 \%$ & $65 \%$ & $20 \%$ & - \\
\hline evaporation & $25 \%$ & $50 \%$ & $25 \%$ & - \\
\hline expansion & $5 \%$ & $75 \%$ & $20 \%$ & - \\
\hline $\begin{array}{l}\text { movement } \\
\text { of electrons } \\
\text { in metals }\end{array}$ & $10 \%$ & $60 \%$ & $30 \%$ & - \\
\hline $\begin{array}{l}\text { sound } \\
\text { propagation }\end{array}$ & $40 \%$ & $50 \%$ & $10 \%$ & - \\
\hline
\end{tabular}

Table 2. Categorization of Pupils' explanations for each phenomenon (post)

\begin{tabular}{|l|c|c|c|c|}
\hline & \multicolumn{4}{|c|}{ Explanations - post } \\
\hline & Initial & $\begin{array}{c}\text { Alterna } \\
\text { ive }\end{array}$ & Correct & Complete \\
\hline solid & - & $25 \%$ & $25 \%$ & $50 \%$ \\
\hline liquid & - & $25 \%$ & $25 \%$ & $50 \%$ \\
\hline gas & - & $25 \%$ & $25 \%$ & $50 \%$ \\
\hline evaporation & & $20 \%$ & $40 \%$ & $40 \%$ \\
\hline expansion & & $20 \%$ & $35 \%$ & $45 \%$ \\
\hline $\begin{array}{l}\text { movement } \\
\text { of electrons } \\
\text { in metals }\end{array}$ & - & $25 \%$ & $15 \%$ & $60 \%$ \\
\hline $\begin{array}{l}\text { sound } \\
\text { propagation }\end{array}$ & & $20 \%$ & $35 \%$ & $45 \%$ \\
\hline
\end{tabular}

With regard to pupils' sketches they were categorized into three basic categories: continuous, microscopic with mistakes and microscopic correct. As shown at Table 3, the great majority of pupils $(75 \%$ and $65 \%)$ drew correct microscopic sketchesafter the intervention instead of microscopic with mistakes (as drawn before the intervention).

Table 3. Categorization of Pupils' sketches for Solids, liquids, gasses and evaporation (prepost)

\begin{tabular}{|l|c|c|c|c|}
\hline & \multicolumn{2}{|c|}{ pre } & \multicolumn{2}{c|}{ post } \\
\hline $\begin{array}{l}\text { Pupils' } \\
\text { Sketches }\end{array}$ & $\begin{array}{l}\text { Solid- } \\
\text { liquid- } \\
\text { gas }\end{array}$ & $\begin{array}{l}\text { Evapo } \\
\text { ration }\end{array}$ & $\begin{array}{l}\text { Solid- } \\
\text { liquid- } \\
\text { gas }\end{array}$ & $\begin{array}{l}\text { Eva } \\
\text { pora } \\
\text { tion }\end{array}$ \\
\hline Continuous & $15 \%$ & $25 \%$ & - & - \\
\hline $\begin{array}{l}\text { Microscopic } \\
\text { with mistakes }\end{array}$ & $65 \%$ & $60 \%$ & $25 \%$ & $35 \%$ \\
\hline $\begin{array}{l}\text { Microscopic } \\
\text { correct }\end{array}$ & $20 \%$ & $15 \%$ & $75 \%$ & $65 \%$ \\
\hline
\end{tabular}

Some characteristic examples of pupils' sketches in each category (continuous, microscopic with mistakes, microscopic correct) are presented at the figure 5 .
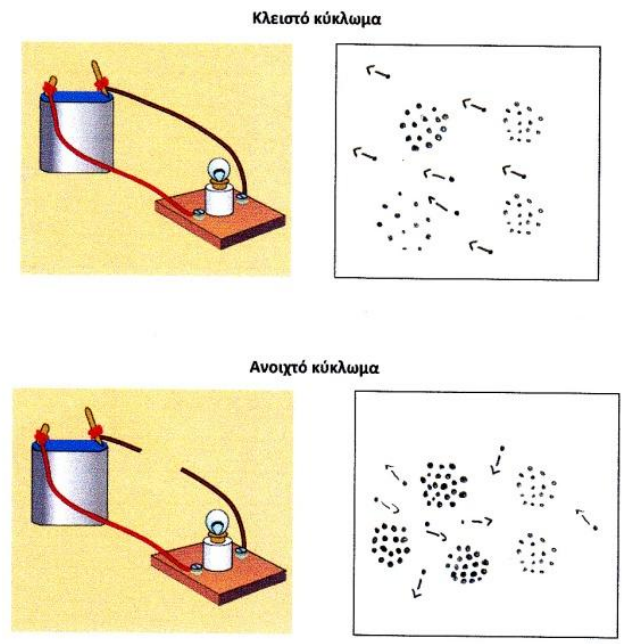

\section{Figure 5. Student's sketches about electric current in metals}

In order to examine our hypothesis concerning the effectiveness of our intervention we compared pupils' answers at the pre-tests and post-tests in all tasks. The Paired Samples T-Tests that were performed showed statistical significant differences in favor of the post-tests in all of the phenomena. Namely, solid: $\mathrm{t}(19)=-6,328, \mathrm{p} \leq 0,001$ (mean pre: 2,10/4, mean post: $3,25 / 4)$, liquid: $\mathrm{t}(19)=-6,439, \mathrm{p} \leq$ 0,001 (mean pre: 2,05/4, mean post: $3,25 / 4$ ), gas: $\mathrm{t}(19)=-6,439, \mathrm{p} \leq 0,001$ (mean pre: $2,05 / 4$, mean post: $3,25 / 4)$, evaporation: $\mathrm{t}(19)=-6,000, \mathrm{p} \leq 0,001$ (mean pre: 2,00/4, mean post: 3,20/4), expansion: $\mathrm{t}(19)=-6,242, \mathrm{p} \leq 0,001$ (mean pre: $2,15 / 4$, mean post: 3,25/4), movement of electrons in metals: $\mathrm{t}(19)=-5,339, \mathrm{p} \leq 0,001$ (mean pre: 2,20/4, mean post: $3,40 / 4)$, sound propagation $\mathrm{n}: \mathrm{t}(19)=-9,131, \mathrm{p} \leq$ 0,001 (mean pre: $1,70 / 4$, mean post: $3,25 / 4$ ).

Table 4. Pupils' mean performance in the tasks (pre-post)

\begin{tabular}{|l|c|c|c|c|}
\hline \multirow{2}{*}{} & \multicolumn{2}{|c|}{ pre } & \multicolumn{2}{c|}{ post } \\
\cline { 2 - 5 } & mean & $\begin{array}{c}\text { st. } \\
\text { dev. }\end{array}$ & mean & $\begin{array}{c}\text { st. } \\
\text { dev. }\end{array}$ \\
\hline solid & $2,10 / 4$ &, 641 & $3,25 / 4$ &, 851 \\
\hline liquid & $2,05 / 4$ &, 605 & $3,25 / 4$ &, 851 \\
\hline gas & $2,05 / 4$ &, 605 & $3,25 / 4$ &, 851 \\
\hline evaporation & $2,00 / 4$ &, 725 & $3,20 / 4$ &, 768 \\
\hline expansion & $2,15 / 4$ &, 489 & $3,25 / 4$ &, 786 \\
\hline $\begin{array}{l}\text { movement } \\
\text { of electrons } \\
\text { in metals }\end{array}$ & $2,20 / 4$ &, 616 & $3,40 / 4$ &, 821 \\
\hline $\begin{array}{l}\text { sound } \\
\text { propagation }\end{array}$ & $1,70 / 4$ &, 657 & $3,25 / 4$ &, 786 \\
\hline
\end{tabular}




\section{Conclusions}

These results seem to confirm our hypothesis since we found that the proposed intervention improved significantly pupils' performance in all areas. Pupils were able to provide more accurate explanations closer to the scientific ones. These results are in accordance with other studies [8, 9], who argue that this understanding of phenomena that cannot be observed helps pupils consolidate their understanding of matter.

With regard to the attitudes questionnaire, several factors were tested: interest, anxiety, difficulty and understanding. Pupilswere asked to answer the questions based on the scale: 1 . I strongly disagree, 2. I disagree, 3. I agree, 4. I strongly agree. To avoid random answers, there were also inverse questions (eg the lesson was interesting, the lesson was boring). The last question asked pupils to answer whether they would like to use relevant software in other lessons.

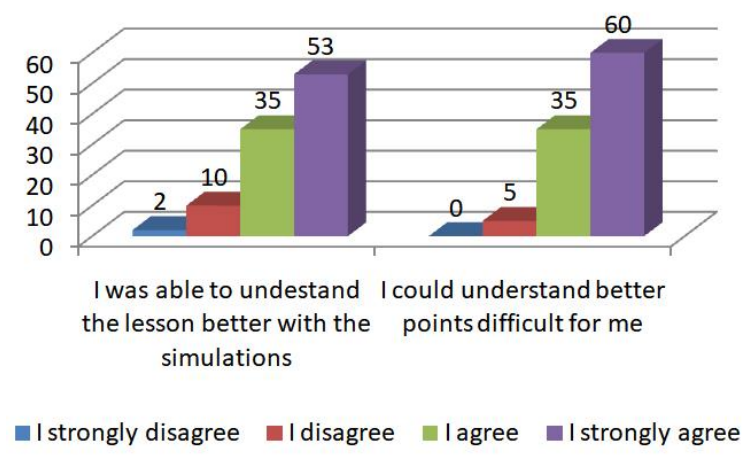

Figure 5. Pupil's opinions about the use of the software

The analysis of the attitudes questionnaire (as well as the in situ observation) revealed the positive response of the pupils, who were very enthusiastic with the application and did not face particular difficulties, as it can be seen most clearly in figure 5 . Moreover all of the pupils answer that they would like to use relevant software in other lessons.

\section{Future Scope}

Based on the evaluation and the results of the current study we are already finished developing more phenomena including molecule structure, photons, and dissolvement and mix of liquids.

\section{References}

[1] Apostolakis E., Panagopoulou E., Savas S., Tsagliotis N., Makri V., Pantazis G., Petrea K., Sotiriou S., Tolias V., Tsagkogeorga A., and Kalkanis G. (2006). Official Science Handbooks for the 5th and 6th grade of Primary Education
"Science - I Investigate and Discover", Greek Ministry of Education - Pedagogical Institute, Athens, 2006.

[2] Bouwma - Gearhart J., Stewart J., and Brown K., (2009). "Student Misapplication of a Gas-like Model to Explain Particle Movement in Heated Solids: Implications for curriculum and instruction towards students' creation and revision of accurate explanatory models". International Journal of Science Education, 31[9], pp. 1157-1174.

[3] Dimopoulos, V., Kalkanis, G. (2003), "An introduction of microcosmos quantum model to students of limited mathematics and science background supported by computer simulations / visualizations", 4th ESERA Conference, "Research and the quality of science education", The Netherlands, Noordwijkerhout, August 1923,2003

[4] Drolapas A., Kalkanis G., (2011), "An inquiry process of electing an educational model of the atom that would be valid for simulations of physical phenomena" $/ 7^{\text {th }}$ Hellenic Conference of Kodipheet. Teaching Science and ICT in Education, Democritus University of Thrace, Alexandroupoli, 15-17 April 2011,http://microkosmos.uoa.gr/gr/publications/articles/Drolapas_Kalkanis_ 2011.pdf (1 December 2018)

[5] Gikopoulou O., (2017). "The Understanding of the model of microcosm in Primary and Secondary Education". International Journal of Digital Society (IJDS), Volume 8, Issue 2, June2017, http://infonomicssociety.org/wp-content/uploads/ijds/publishedpapers/volume-8-2017/The-Understanding-of-the-Modelof-Microcosm-in-Primary-and-Secondary-Education.pdf (1 December 2018)

[6] Kalkanis G., (2013). "From the Scientific to the Educational: Using Monte Carlo Simulations of the microKosmos for Science Education by Inquiry". Chapter in Book: Concepts of Matter in Science Education, editors Georgios Tsaparlis and Hannah Sevian, Springer.

[7] Merritt J., and Krajcik J. (2013). "Learning Progression Developed to Support Students in Building a Particle Model of Matter", Book Concepts of Matter in Science Education, Springer Series "Innovations in Science Education and Technology", Eds G. Tsaparlis and H. Sevian, Springer 2013, Vol. 19, p.11-45

[8] Wiser M., Frazier K., and Fox V., (2013). "At the Beginning was Amount of Material: A Learning Progression for Matter for Early Elementary Grades", Chapter in Book "Concepts of Matter in Science Education", Springer Series "Innovations in Science Education and Technology", Editors Tsaparlis, Sevian, Springer Dordrecht Heidelberg New York London, Vol. 19

[9] Wiser M., and Smith C., (2008). "Teaching about matter in grades K-8: When should the atomic-molecular theory be introduced?" Chapter in International Handbook of Research on Conceptual Change, Edited by Stella Vosniadou 